\title{
Ultrafine Silica Additives Behavior during Alkali-Silica Reaction Long-Term Expansion Test
}

\author{
Alexey Brykov ${ }^{1}$, Mikhail Voronkov', ${ }^{1}$ Maxim Mokeev $^{2}$ \\ ${ }^{1}$ Department of Technology of Constructional and Special Binders, Faculty of Chemistry of Substances and Materials, St. Petersburg \\ State Institute of Technology, St. Petersburg, Russia; ${ }^{2}$ Institute of High-Molecular Compounds, Russian Academy of Sciences, St. \\ Petersburg, Russia. \\ Email: brykov@yahoo.com
}

Received November $12^{\text {th }}, 2013$; revised December $19^{\text {th }}, 2013$; accepted January $12^{\text {th }}, 2014$

Copyright (c) 2014 Alexey Brykov et al. This is an open access article distributed under the Creative Commons Attribution License, which permits unrestricted use, distribution, and reproduction in any medium, provided the original work is properly cited. In accordance of the Creative Commons Attribution License all Copyrights (C) 2014 are reserved for SCIRP and the owner of the intellectual property Alexey Brykov et al. All Copyright (C 2014 are guarded by law and by SCIRP as a guardian.

\section{ABSTRACT}

A silica fume, precipitated silica, metakaolin and siliceous fly ash behavior as constituents of mortars was studied, while mortar samples have been tested for long-term alkali-silica reaction expansion in accordance to the GOST 8269.0 specification. Solid-state ${ }^{29}$ Si-MAS NMR spectroscopy and thermogravimetric analysis were used to describe Portland cement hydration, supplementary cementitious material pozzolanic reaction and to establish a structure of products of those processes. It was found that long-term test conditions, in contrast to the accelerated test, do not affect the composition of products formed too much, compared to normal conditions. This allows results obtained with long-term test to be expected as more relevant in terms of predicting of supplementary cementitious materials inhibiting properties.

\section{KEYWORDS}

\section{Alkali-Silica Reaction; Supplementary Cementitious Materials; MAS NMR; Thermogravimetric Analysis; Pozzolanic Reaction}

\section{Introduction}

Use of supplementary cementitious materials (SCM) such as silica fume, fly ash or metakaolin, is known to be the most efficient way of Alkali-Silica Reactions (ASR) suppressing [1-6] nowadays. Those fine, well dispersed SCM are also known as pozzolans and possess an ability to bind $\mathrm{Ca}(\mathrm{OH})_{2}$ forming $\mathrm{C}-\mathrm{S}-\mathrm{H}$.

There's still much to be considered about ASR and how supplementary additives help to stop it $[7,8]$. Despite such additives being successfully used on practice to prevent and inhibit ASR, it's yet unclear about their long-term efficacy $[8,9]$. Methods to evaluate the concrete component reactivity to alkalis, hence to predict the concrete expansion, usually deal with high temperature and high $\mathrm{pH}$ conditions of storing samples $[8,10]$. Obviously, these conditions differ from typical concrete structure operation environment.

By means of solid-state nuclear magnetic resonance
(NMR) and thermogravimetric analysis (TGA), a silica fume, metakaolin and precipitated silica behavior as constituents of mortar mixtures was investigated in [11]. Sample storage and expansion measurements were performed in close accordance with GOST 8269.0 requirements, which are alike to those set in other national standards world-wide, such as ASTM C1260 (mortar bar method). The principal points are to store samples submerged in $1 \mathrm{~N} \mathrm{NaOH}$ water solution at $80^{\circ} \mathrm{C}$. All of the SCMs used were observed to react with $\mathrm{Ca}(\mathrm{OH})_{2}$ quickly under these conditions. No considerable difference was noted in SCM additives inhibiting effect on ASR, which is interpreted as additives' particle dissolve in pore fluid before concrete expansion is provoked by putting samples in the alkali solution, therefore neither the initial particles' sizes nor their specific surface areas matter anymore in terms of ASR suppression. Additional observation discovered that even fly ash which is known to get into pozzolanic reaction at a slower pace, keeps up 
with silica fume and metakaolin, so all three additives possess about the same ability to control concrete alkali expansion (Figure 1).

What also been noted is that by using the accelerated test method, a ratio of Portland cement (PC) hydration to SCM reaction rate differs much from the same evaluated under normal conditions - the fact that has an influence on the composition of PC/SCMs hydration products. All above said means that there may be no way to accurately compare SCMs as ASR suppressors under abnormal conditions of accelerated test.

There is also a prolonged alkali expansion evaluation method described in GOST 8269.0 (concrete prism method), ordering to store concrete samples at $38^{\circ} \mathrm{C}\left(100^{\circ} \mathrm{F}\right)$, $100 \% \mathrm{RH}$. One may suggest that this would let for better ranging of SCMs considering their ASR inhibiting activity.

The objective of this work is to study the metamorphosis of siliceous additives (silica fume, precipitated silica, metakaolin and siliceous fly ash) as a constituent of mortar samples stored and tested in accordance to GOST 8269.0 long-term method specification.

\section{Experimental}

\subsection{Materials}

The following materials were used:

Portland cement CEMI $42.5 \mathrm{R}$ with the following phase composition, wt. \%: $\mathrm{C}_{3} \mathrm{~S} 52-53, \mathrm{C}_{2} \mathrm{~S} 17-18, \mathrm{C}_{3} \mathrm{~A}+$ $\mathrm{C}_{4} \mathrm{AF} 20$ - 22, gypsum 4 - 5, $\mathrm{Na}_{2} \mathrm{O}_{\mathrm{e}}$ 0.4; Quartz sand

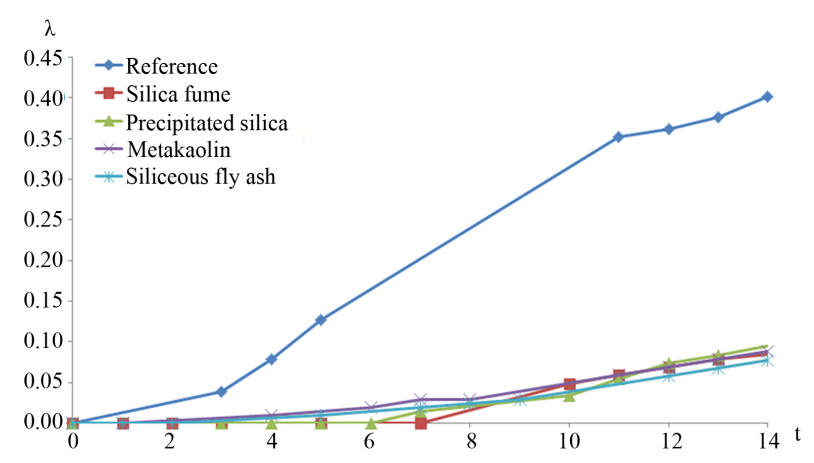

Figure 1. Mortar samples extension $\lambda(\%)$ with time $t$ (days) at accelerated test method conditions [11]. containing $7.5 \%$ of chalcedony (by petrographic data); particle size distribution, wt.\%: 1.25 - $2.5 \mathrm{~mm} \mathrm{27.5;0.63}$ - 1.25 mm 27.5; 0.315 - 0.63 mm 27.5; 0.16 - 0.315 mm 17.5 .

Table 1 displays characteristics of SCMs used.

Additives-free mortars serving as reference samples are made of PC and quartz sand (1:2.25), and then mixed with water at water-to-solid ratio of 0.125 . A chemically pure $\mathrm{NaOH}$ was dissolved in mixing water to ensure $1.5 \% \mathrm{Na}_{2} \mathrm{Oe}$ of PC weight (PC alkalis were taken into account). SCM containing mortars were prepared in the same manner while $10 \%$ of PC has being replaced by an additive.

Since putting SCM leads to mortar flowability decrease, a Melflux 2651F superplasticizer being introduced with mixing water. The dosages were: $0.8 \%$ by PC for precipitated silica, $0.1 \%-0.15 \%$ for silica fume and metakaolin.

\subsection{Sample Preparations and Testing Methods}

Mortar mixes are put into $20 \times 20 \times 100 \mathrm{~mm}$ molds. Samples were stored into molds at $20^{\circ} \mathrm{C}, 100 \% \mathrm{RH}$ conditions for the first 2 days. Mortar samples then demolded and samples' length measured. After that, samples were being stored at $38^{\circ} \mathrm{C}, 100 \% \mathrm{RH}$ for the rest of the testing period. Extension measurements were on a monthly base and every time samples were cooled down to $20^{\circ} \mathrm{C}$ before read is taken.

To inspect what is happening to SCM at this conditions and how does PC hydration process is affected by the presence of an additive, cement pastes were prepared by $90 \%$ of PC and $10 \%$ of SCM (by weight), mixed with water at (PC + SCM)-to-water ratio of 0.4 . As in case of mortar samples preparation, an adequate quantity of $\mathrm{NaOH}$ is dissolved in mixing water in order to achieve $1.5 \% \mathrm{Na}_{2} \mathrm{Oe}$ alkalinity. Hardened paste casts are stored under the same conditions as mortar specimens. Using 29 Si-MAS NMR spectroscopy, SCM conversion and PC hydration rates as well as Al-Si-O chains' length in PC + SCM hydration product and Al-to-Si proportion have been established at the age of 2, 7, 30 and 90 days. The amount of $\mathrm{Ca}(\mathrm{OH})_{2}$ was calculated involving TGA data at the same ages.

Table 1. SCM used and their properties.

\begin{tabular}{|c|c|c|c|}
\hline SCM type & Base component, wt.\% & Specific surface area, $\mathrm{m}^{2} / \mathrm{g}$ & Aggregate particles size, $\mu \mathrm{m}$ \\
\hline Densified silica fume MKU-85 (МКУ-85), Novokuznetsk & $\mathrm{SiO}_{2} 91.5$ & 14 & $20-250$ \\
\hline Precipitated silica BS-100 (БC-100), GOST 18307-78 & $\mathrm{SiO}_{2} 90.0$ & 110 & $1-50$ \\
\hline Metakaolin (Brazil) & $\mathrm{SiO}_{2} \sim 53.5 \mathrm{Al}_{2} \mathrm{O}_{3} \sim 46.5$ & 14 & $35-50$ \\
\hline Fly-ash (Reftinsk district power station) & $\mathrm{SiO}_{2} 60.8 \mathrm{Al}_{2} \mathrm{O}_{3} 29.1$ & 0.24 (Blaine) & - \\
\hline
\end{tabular}


Solid state NMR spectra were obtained by Bruker Avance-IIWB-500 solid-state NRM spectrometer (99.35 $\mathrm{MHz}$, rotor spin $10 \mathrm{kHz}$ ). Chemical shifts are referred to TMS signal. Thermogravimetric analysis equipment was Paulik-Paulik-Erdey derivatograph (500 mg sample, heating rate of $10 \mathrm{deg}^{\circ} \mathrm{C} / \mathrm{min}$ ). Specimens for NMR and TGA are prepared as described in [11].

\section{Results and Discussion}

Figure 2 displays $\mathrm{Ca}(\mathrm{OH})_{2}$ content value, which is corrected to initial $\mathrm{PC}$ content in mixes. In such way a pozzolanic activity of SCM can be measured.

Figure 3 shows solid-state NMR spectra of the following samples: dry mix of PC and silica fume, pure PC paste and PC pastes containing silica fume, precipitated silica and fly ash additives. NMR spectra deconvolution is performed by means of Dmfit software, an example is

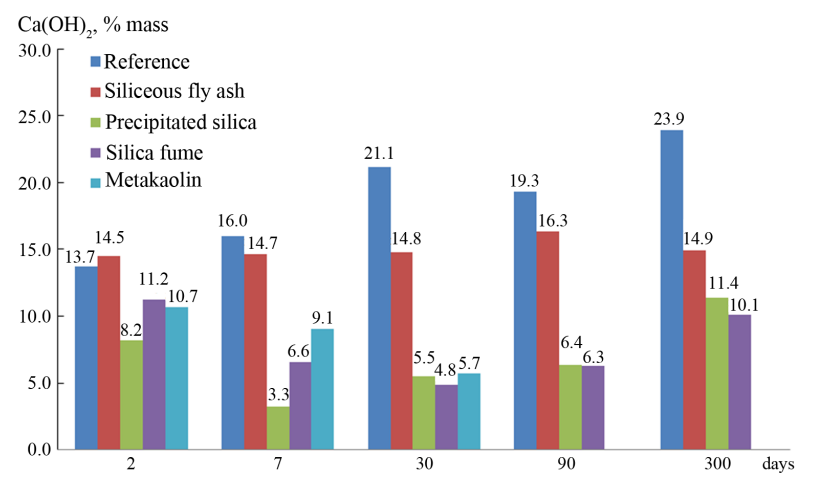

Figure 2. The content of $\mathrm{Ca}(\mathrm{OH})_{2}$ in hardened cement pastes.

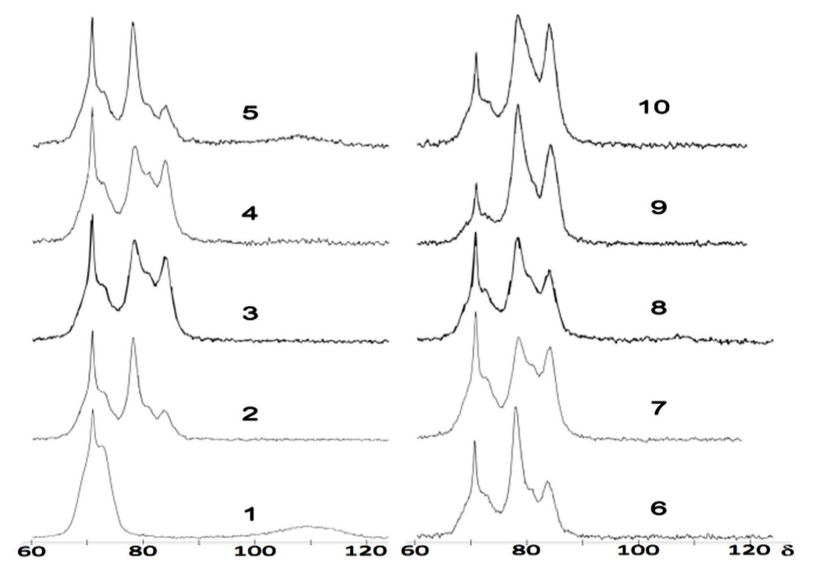

Figure $3 .{ }^{29}$ Si-NMR solid state spectra of: $P C+10 \%$ silica fume dry mix (1); 7-days old mortars of PC with no admixtures (2), mortars containing $10 \%$ of precipitated silica (3), silica fume (4) and fly ash (5) ; 1-month old mortars: PC (6), $10 \%$ silica fume (7) and $10 \%$ fly ash (8); 10-month old mortars: PC (9), $10 \%$ silica fume (10). X-coordinate is a chemical shift value, ppm. shown at Figure 4. Signals are referred in accordance to literature data available [12-15].

Figure 5 represents 10\% metakaolin samples NMR spectra.

Table 2 shows data acquired from spectra shown at Figures 3 and 5 as well as other spectra which are not on pictures.

Using $\mathrm{Q}^{0}$ and $\mathrm{Q}^{4}$ signals strength, an amount of PC hydrated $(\alpha, \%)$ and SCM conversion degree $(\omega, \%)$ have been calculated by formulae described in [16]. An average Al-Si-O chains' length $(n)$ of PC/SCM reaction product and Al-to-Si ratio of chains $(\mathrm{Al} / \mathrm{Si}$ ) are evaluated by formulae [14]. The results are shown in Table 3.

There are also Ca-to-Si $\left(\mathrm{Ca} / \mathrm{Si}_{\mathrm{A}}\right)$ ratios in additives' pozzolanic reaction product, and in shared $\mathrm{C}-\mathrm{S}-\mathrm{H}$ which is produced by both PC hydration and additive reaction $(\mathrm{Ca} / \mathrm{Si})$, measured at various ages.

Ca-to-Si in pozzolanic reaction product is calculated as follows:

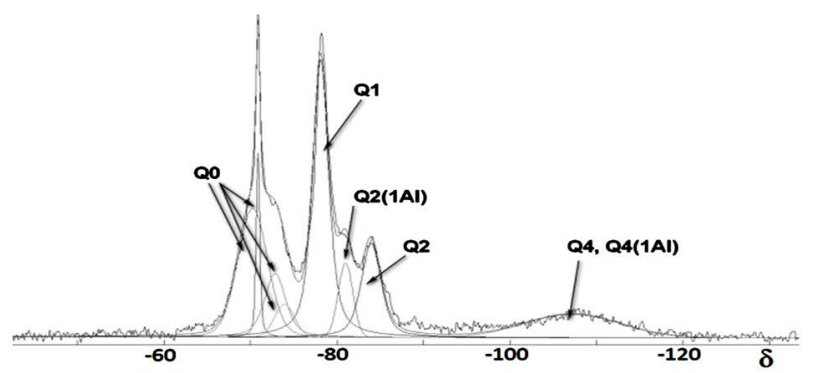

Figure 4. NMR spectrum deconvolution (spectrum 5, Figure 3).

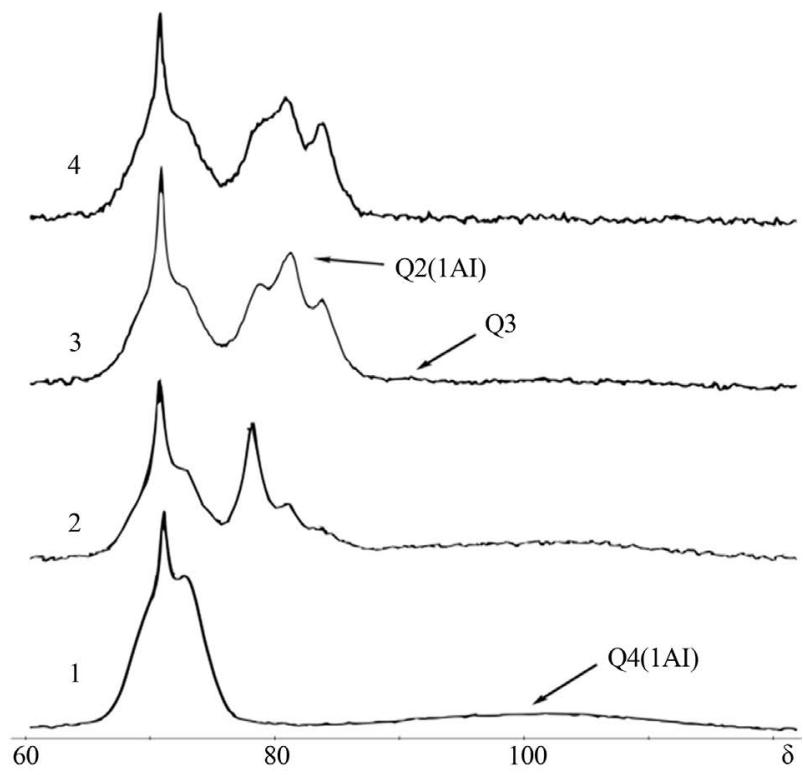

Figure 5. Solid state ${ }^{29} \mathrm{Si}-\mathrm{NMR}$ spectra of $\mathbf{9 0} \%$ OPC $+\mathbf{1 0} \%$ Metakaolin dry mix (1), cement paste containing $10 \%$ of metakaolin at the age of $2,7 \& 30$ days (2 - 4). 
Table 2. Si atoms of various coordination in PC and PC + SCM samples (\%), in accordance to NMR data.

\begin{tabular}{|c|c|c|c|c|c|c|}
\hline SCM type and quantity & Age, days & $\mathrm{Q}^{0}$ & $\mathrm{Q}^{1}$ & $\mathrm{Q}^{2}(1 \mathrm{Al})$ & $\mathrm{Q}^{2}$ & $Q^{4^{*}}$ \\
\hline \multirow{5}{*}{ no additives } & 2 & 60.79 & 27.07 & 6.54 & 6.61 & 0.00 \\
\hline & 7 & 46.57 & 35.24 & 6.34 & 11.85 & 0.00 \\
\hline & 30 & 33.87 & 38.39 & 7.40 & 20.34 & 0.00 \\
\hline & 90 & 28.00 & 39.14 & 7.92 & 24.93 & 0.00 \\
\hline & 300 & 17.47 & 40.13 & 10.56 & 31.85 & 0.00 \\
\hline \multirow{6}{*}{ Silica fume. $10 \%$} & dry mix & 78.05 & 0.00 & 0.00 & 0.00 & 21.96 \\
\hline & 2 & 45.06 & 24.38 & 5.23 & 6.37 & 18.97 \\
\hline & 7 & 38.56 & 24.84 & 9.98 & 23.36 & 3.25 \\
\hline & 30 & 36.38 & 26.99 & 12.27 & 24.35 & 0.00 \\
\hline & 90 & 32.93 & 30.43 & 8.86 & 27.77 & 0.00 \\
\hline & 300 & 23.67 & 29.33 & 15.68 & 31.32 & 0.00 \\
\hline \multirow{6}{*}{ Precipitated silica. 10\% } & dry mix & 76.76 & 0.00 & 0.00 & 0.00 & 23.23 \\
\hline & 2 & 49.42 & 23.81 & 5.21 & 6.07 & 15.49 \\
\hline & 7 & 38.24 & 27.08 & 9.42 & 25.27 & 0.00 \\
\hline & 30 & 30.02 & 31.00 & 13.19 & 25.79 & 0.00 \\
\hline & 90 & 24.45 & 36.51 & 9.70 & 29.35 & 0.00 \\
\hline & 300 & 14.79 & 37.10 & 12.90 & 35.21 & 0.00 \\
\hline \multirow{4}{*}{ Metakaolin. 10\% } & dry mix & 73.47 & 0.00 & 0.00 & 0.00 & 26.52 \\
\hline & 2 & 40.88 & 22.96 & 5.49 & 6.02 & 24.64 \\
\hline & 7 & 43.88 & 17.08 & 17.73 & $13.01\left(Q^{3} 2.33\right)$ & 5.97 \\
\hline & 30 & 49.51 & 20.48 & 14.84 & 15.16 & 0.00 \\
\hline \multirow{6}{*}{ Fly ash. $10 \%$} & dry mix & 87.54 & 0.00 & 0.00 & 0.00 & 12.46 \\
\hline & 2 & 49.00 & 24.93 & 4.30 & 6.56 & 15.20 \\
\hline & 7 & 38.81 & 30.84 & 5.89 & 12.40 & 12.06 \\
\hline & 30 & 33.75 & 31.33 & 10.83 & 20.98 & 3.12 \\
\hline & 90 & 27.55 & 33.78 & 8.73 & 29.94 & 0.00 \\
\hline & 300 & 18.74 & 34.97 & 13.13 & 33.16 & 0.00 \\
\hline
\end{tabular}

${ }^{*}$ metakaolin— $\mathrm{Q}^{4}(1 \mathrm{Al})$, fly ash- $\left(\mathrm{Q}^{4}+\mathrm{Q}^{4}(1 \mathrm{Al})\right)$.

$$
\mathrm{Ca} / \mathrm{Si}_{A}=\frac{\frac{\alpha_{\mathrm{A}}}{\alpha_{P C}} \times \mathrm{Ca}(\mathrm{OH})_{2}^{P C}-\mathrm{Ca}(\mathrm{OH})_{2}^{A}}{M_{\mathrm{Ca}(\mathrm{OH})_{2}} \times\left(\frac{\mathrm{SiO}_{2}^{A}}{M_{\mathrm{SiO}_{2}}}+\frac{\mathrm{Al}_{2} \mathrm{O}_{3}^{A}}{M_{\mathrm{Al}_{2} \mathrm{O}_{3}}}\right) \times K}
$$

where: $\alpha_{P C}, \alpha_{A}-\mathrm{PC}$ hydration degree in control sample and additive-containing sample, accordingly; $\mathrm{Ca}(\mathrm{OH})_{2}{ }^{P C}$, $\mathrm{Ca}(\mathrm{OH})_{2}{ }^{\mathrm{A}}-\mathrm{Ca}(\mathrm{OH})_{2}$ contained in PC sample and PC + additive sample, wt. \%; $\mathrm{SiO}_{2}{ }^{\mathrm{A}}, \mathrm{Al}_{2} \mathrm{O}_{3}{ }^{\mathrm{A}}$ - content of $\mathrm{SiO}_{2}$ and $\mathrm{Al}_{2} \mathrm{O}_{3}$ in additive, wt. \%; $\mathrm{M}_{\mathrm{Ca}(\mathrm{OH}) 2}, \mathrm{M}_{\mathrm{SiO} 2}, \mathrm{M}_{\mathrm{Al2} 23}-$ molar weight of $\mathrm{Ca}(\mathrm{OH})_{2}, \mathrm{SiO}_{2}$ and $\mathrm{Al}_{2} \mathrm{O}_{3}$, g/mole; $K-$ the weight ratio of additive to PC in sample ( $K=1 / 9$ for $90 \%$ of PC and $10 \%$ of SCM).

A Ca-to-Si ratio of shared C-S-H was calculated as follows:

$$
\mathrm{Ca} / \mathrm{Si}=\frac{\frac{3 \mathrm{C}_{3} \mathrm{C}}{M_{\mathrm{C}_{3} \mathrm{~S}}}+\frac{3 \mathrm{C}_{2} \mathrm{C}}{M_{\mathrm{C}_{2} \mathrm{~S}}}-\frac{\mathrm{Ca}(\mathrm{OH})_{2}}{M_{\mathrm{Ca}(\mathrm{OH})_{2}} \times \alpha}}{\frac{\mathrm{C}_{3} \mathrm{C}}{M_{\mathrm{C}_{3} \mathrm{~S}}}+\frac{\mathrm{C}_{2} \mathrm{C}}{M_{\mathrm{C}_{2} \mathrm{~S}}}+\frac{K \times \omega}{100 \times \alpha} \times\left(\frac{\mathrm{SiO}_{2}}{M_{\mathrm{SiO}_{2}}}+\frac{\mathrm{Al}_{2} \mathrm{O}_{3}}{M_{\mathrm{Al}_{2} \mathrm{O}_{3}}}\right)}
$$

where: $\mathrm{C}_{3} \mathrm{~S}, \mathrm{C}_{2} \mathrm{~S}$ are alit and belite contents in PC, wt.\%, $\mathrm{M}_{\mathrm{C} 3 \mathrm{~s}}, \mathrm{M}_{\mathrm{C} 2 \mathrm{~S}}, \mathrm{M}_{\mathrm{Ca}(\mathrm{OH}) 2}-$ molar weights, g/mole, $\alpha, \omega$ are 
Table 3. Samples' parameters based on NRM and TGA data obtained.

\begin{tabular}{|c|c|c|c|c|c|c|c|}
\hline SCM type and quantity & Age, days & $\alpha, \%$ & $\omega, \%$ & $\mathrm{n}$ & $\mathrm{Al} / \mathrm{Si}$ & $\mathrm{Ca} / \mathrm{Si}_{\mathrm{CSH}}$ & $\mathrm{Ca} / \mathrm{Si}_{\mathrm{A}}$ \\
\hline \multirow{5}{*}{ no additives } & 2 & 39.2 & 0.0 & 3.2 & 0.08 & 1.26 & - \\
\hline & 7 & 53.4 & 0.0 & 3.2 & 0.06 & 1.47 & - \\
\hline & 30 & 66.1 & 0.0 & 3.6 & 0.06 & 1.39 & - \\
\hline & 90 & 72.0 & 0.0 & 3.9 & 0.06 & 1.60 & - \\
\hline & 300 & 82.5 & 0.0 & 4.4 & 0.06 & 1.51 & - \\
\hline \multirow{5}{*}{ Silica fume. $10 \%$} & 2 & 42.3 & 13.6 & 3.2 & 0.07 & 1.36 & 2.13 \\
\hline & 7 & 50.6 & 85.2 & 5.1 & 0.09 & 1.11 & 0.81 \\
\hline & 30 & 53.4 & 100.0 & 5.2 & 0.10 & 1.13 & 0.99 \\
\hline & 90 & 57.8 & 100.0 & 4.7 & 0.07 & 1.14 & 0.74 \\
\hline & 300 & 69.7 & 100.0 & 5.7 & 0.10 & 1.16 & 0.82 \\
\hline \multirow{5}{*}{ Precipitated silica. 10\% } & 2 & 35.6 & 33.3 & 3.2 & 0.07 & 1.15 & 1.04 \\
\hline & 7 & 50.2 & 100.0 & 4.9 & 0.08 & 1.15 & 0.95 \\
\hline & 30 & 60.9 & 100.0 & 4.9 & 0.09 & 1.21 & 1.13 \\
\hline & 90 & 68.2 & 100.0 & 4.4 & 0.06 & 1.27 & 0.96 \\
\hline & 300 & 80.7 & 100.0 & 4.9 & 0.08 & 1.25 & 0.97 \\
\hline \multirow{3}{*}{ Metakaolin. 10\% } & 2 & 44.4 & 7.1 & 3.2 & 0.08 & 1.57 & - \\
\hline & 7 & - & 77.4 & 6.6 & 0.19 & - & - \\
\hline & 30 & - & 100.0 & 5.6 & 0.15 & - & - \\
\hline \multirow{5}{*}{ Fly ash. $10 \%$} & 2 & 44.0 & 0.0 & 3.0 & 0.06 & 1.35 & - \\
\hline & 7 & 55.7 & 3.2 & 3.4 & 0.06 & 1.57 & - \\
\hline & 30 & 61.4 & 75.0 & 4.4 & 0.09 & 1.02 & 0.62 \\
\hline & 90 & 68.5 & 100.0 & 4.5 & 0.06 & 0.94 & 0.62 \\
\hline & 300 & 78.6 & 100.0 & 5.0 & 0.08 & 1.12 & 0.74 \\
\hline
\end{tabular}

the degrees of hydration of PC and additive respectively, $K$ is an additive to cement weight ratio (1/9), $\mathrm{SiO}_{2}$, $\mathrm{Al}_{2} \mathrm{O}_{3}$ - content of $\mathrm{SiO}_{2}$ and $\mathrm{Al}_{2} \mathrm{O}_{3}$ in additive, wt.\%.

There are signals in area of $-(67-75) \mathrm{ppm}$ at spectrum 1 in Figure 3 (dry mix of PC $+10 \%$ silica fume), referring to "island" tetrahedra $\mathrm{SiO}_{4}$ of silicate phases of PC, which is denoted as $\mathrm{Q}^{0}$; a broad signal at $-(100-120)$ ppm is $\mathrm{Q}^{4}$ belonged to non-crystalline structure of silica fume. The spectra of mixes of PC with precipitated $\mathrm{SiO}_{2}$ and fly ash aren't shown since they look in the same fashion; the spectrum of fly ash has a broad $\left(\mathrm{Q}^{4}+\mathrm{Q}^{4}(1 \mathrm{Al})\right)$ signal in area of $-(95-120)$ with a maximum at -108 $\mathrm{ppm}$. The signal of metakaolin $\left(\mathrm{Q}^{4}(1 \mathrm{Al})\right)$ is in the region of $-(90-110)$ ppm with a maximum at $-101 \mathrm{ppm}$ (spectrum 1, Figure 5).

Spectrum 2 in Figure 3 represents the reference sample of 7 days old. The signal of C-S-H is in -(78 - 85) ppm area. The structure of C-S-H consists of short chains of $\mathrm{SiO}_{4}$ tetrahedra, including some $\mathrm{AlO}_{4}$ tetrahedron links. A $\mathrm{Q}^{2}$ signal at $-(84-85)$ ppm belongs to Si nuclei: those being inner links of $\mathrm{SiO}_{4}$ chains. A strong broad signal at -(78 - 82) ppm is actually a superposition of two different signals $[12,14]$ (see Figure 4$)$, their peaks are at $-(78$ - 80), $-(80$ - 82) $\mathrm{ppm}$. The first one corresponds to outer links of chains $\left(\mathrm{Q}^{1}\right)$, and the second one-to those Si nuclei, which have a neighbor $\mathrm{Al}$ nucleus (-Si-O-Si-O-Al-), these denoted as $\mathrm{Q}^{2}(1 \mathrm{Al})$.

Spectra 3 - 5 are those of 7-days old PC pastes with precipitated silica, silica fume and fly ash additives accordingly. Spectrum 3 observes no signal of SCM, so the additive conversion ratio is said to be $100 \%$ and the whole amount of additive substance is now incorporated into C-S-H gel structure. There's a pretty short time needed for the reaction to complete, this may be due to high specific surface area of precipitated silica's particles. Silica fume possesses about the same reactivity, its $Q^{4}$ 
signal is considerably weakened, and so only $15 \%$ of silica fume remains unreacted.

It should be noted that when $\mathrm{Q}^{4}$ decay, $\mathrm{Q}^{2}$ and $\mathrm{Q}^{2}(1 \mathrm{Al})$ arise at the same time (see Figure 3, Table 2).This is considered as C-S-H chains elongation in the presence of SCM as compared to pure PC samples. Silica fume is fully consumed within 7 days to 1 month period.

Metakaolin is close to silica fume in its reaction rate and is consumed completely within a month. However, the structure of C-S-H chains in presence of metakaolin differs from the one produced when other additives are used: more $\mathrm{Al}$ nuclei embed into chains which is observed as $\mathrm{Q}^{2}(1 \mathrm{Al})$ signal grows up and $\mathrm{Q}^{1}$ intensity decrease, so the longest and the most aluminum-rich chains appear. Al-to-Si ratio is also the highest among other SCM additives.

Almost the whole amount of fly ash persists untouched to $7^{\text {th }}$ day of hydration. At the age of one month $25 \%$ still remains and the total conversion takes place between 1 to 3 months.

$\mathrm{A} \mathrm{Ca}(\mathrm{OH})_{2}$ content in samples agrees with SCM reactivity (Figure 2). Sample with precipitated silica has lowest amount of $\mathrm{Ca}(\mathrm{OH})_{2}$ in paste for the first days of hydration and the minimum is reached at about 7 days. At later stages, $\mathrm{Ca}(\mathrm{OH})_{2}$ content is about the same for precipitated silica, silica fume and metakaolin containing samples. Unlike other additives, fly ash possess the least intensive $\mathrm{Ca}(\mathrm{OH})_{2}$ binding behavior during the whole test period, reacting with $\mathrm{Ca}(\mathrm{OH})_{2}$ at a steady pace and keeping its level at $14 \%-16 \%$. As it seems, in this case $\mathrm{Ca}(\mathrm{OH})_{2}$ release and binding rates are pretty much equal.

As is shown in Table 3, the Ca-to-Si of C-S-H gel formed by an additive is in 0.7 - 1 range, meanwhile additive-free PC produces C-S-H with this ratio of 1.5 - 1.6. A shared C-S-H formed by both PC hydration and SCM reaction has an average ratio of $1.0-1.3$. As is seen, SCMs reduce Ca-to-Si molar ratio in C-S-H.

Figure 6 represents extension curves of various samples during the GOST 8269.0 alkali expansion test. As it clearly seen, adding $10 \%$ of fly ash gives no any visible effect on sample alkaline extension. At one year, fly ash containing specimen shows twice the critical expansion value of $0.04 \%$ which is very close to SCM-free reference sample, i.e. no any positive effect is observed. A literature points out [6] that to suppress alkali-silica reaction processes, at least $20 \%-25 \%$ of siliceous fly ash must be used to make a concrete.

Samples with $10 \%$ of silica fume or precipitated silica fits within $0.04 \%$ expansion limit, albeit barely. Alkali expansion decelerates with time so at later stages the expansion is almost stopped. This is in agreement with [6], where it's mentioned that $10 \%-15 \%$ of silica fume helps keeping the extension below the critical threshold while test procedure is carried out with ASTM 1293 requirements, which are similar to GOST 8269.0.

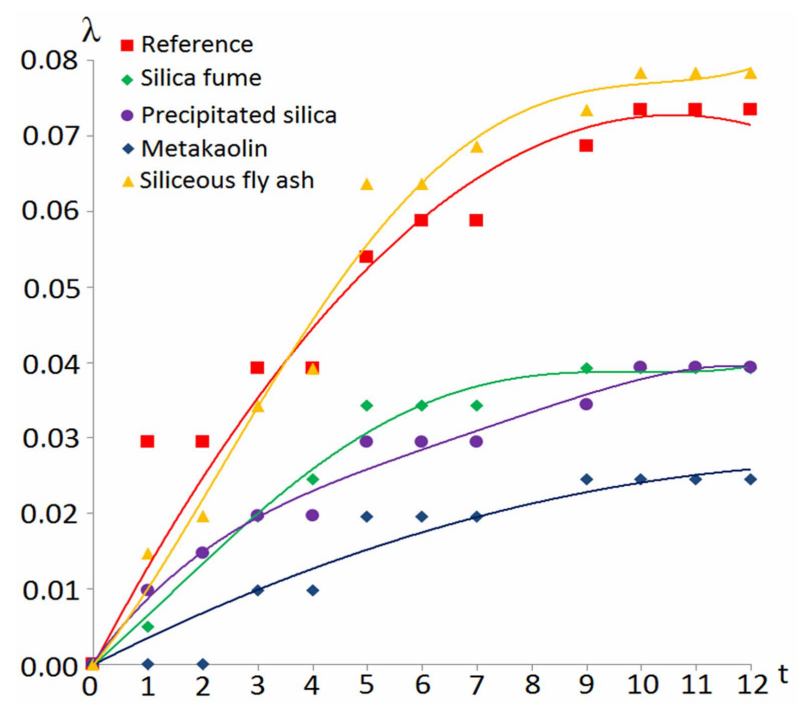

Figure 6. Mortar samples extension $\lambda(\%)$ with time (days) under long-term concrete samples test conditions (GOST 8269.0).

Among three the most efficient additives-silica fume, precipitated silica and metakaolin-no definite correlation can be established between theirs reactivity, $\mathrm{Ca}(\mathrm{OH})_{2}$ binding rate and ASR inhibiting ability. While it's precipitated silica that possess the most specific surface area, metakaolin shows the best effect on alkali expansion suppression. It can be concerned with its ability to form elongated chains of aluminum rich C-S-H; see also [17]. In accordance to NMR data, use of SCM do not affect PC hydration rate. At least for the initial period of test, the difference between PC hydration in SCM-containing and SCM-free specimens are within the measurements accuracy. Using Table 3 data one may compare the degree of PC hydrated on various points of experiment: for 2 days old samples this value lays between $35 \%$ and $44 \%$, to the age of 7 and 30 days-50\% - 53\% and 53\% - 66\% accordingly, and for 3 and 10 months-58\% - 72\%, 70\% - $82 \%$. One must emphasize that under accelerated test method conditions using SCM drops the rate of Portland cement hydration significantly [11].

\section{Conclusions}

1) Accelerated mortar bar test levels off different ultrafine silica additives in their ability to control the concrete expansion due to ASR, which is because all of them got bound with $\mathrm{Ca}(\mathrm{OH})_{2}$ quickly.

2) A long-term concrete sample test makes various additives to go into reaction at various points, from several days to months, which makes it easier to separate them in terms of ASR inhibiting ability.

3) C-S-H gel formed in the presence of metakaolin is of highest Al-to-Si ratio $(0.15-0.19)$ and has the longest chains' length ( 6 of $\mathrm{Si}, \mathrm{Al}$ nuclei), which is, likely, be- 
cause of aluminum incorporation into gel structure. This could make areas on for metakaolin to be the best ASR suppressor among other additives used in the experiment.

\section{REFERENCES}

[1] G. Gudmundsson and H. Olafsson, "Alkali-Silica Reactions and Silica Fume. 20 Years of Experience in Iceland,” Cement and Concrete Research, Vol. 29, No. 8, 1999, pp. 1289-1297. http://dx.doi.org/10.1016/S0008-8846(98)00239-7

[2] A. Pool and I. Sims, “Alkali-Aggregate Reactivity,” In: J. Newman and B. S. Choo, Eds., Advanced Concrete Technology. Concrete Properties, Elsevier, Berlin, 2003, pp. 13/1-13/37.

[3] T. Ramlochan, M. Thomas and K. Gruber, "The Effect of Metakaolin on Alkali-Silica Reaction in Concrete," Cement and Concrete Research, Vol. 30, No. 3, 2000, pp. 339-344. http://dx.doi.org/10.1016/S0008-8846(99)00261-6

[4] M. Shehata and M. Thomas, "Use of Ternary Blends Containing Silica Fume and Fly Ash to Suppress Expansion Due to Alkali-Silica Reaction in Concrete,” Cement and Concrete Research, Vol. 32, No. 3, 2002, pp. 341349. http://dx.doi.org/10.1016/S0008-8846(01)00680-9

[5] M. Thomas, "The Effect of Supplementary Cementing Materials on Alkali-Silica Reaction: A Review," Cement and Concrete Research, Vol. 41, No. 12, 2011, pp. 12241231. http://dx.doi.org/10.1016/j.cemconres.2010.11.003

[6] M. Thomas and K. Folliard, "Concrete Aggregates and the Durability of Concrete,” In: C. Page and M. Page, Eds., Durability of Concrete and Cement Composites, CRC Press, Boca Raton, 2007, pp. 247-281. http://dx.doi.org/10.1533/9781845693398.247

[7] X. Hou, L. Struble and R. Kirkpatrick, "Formation of ASR Gel and the Roles of C-S-H and Portlandite," $\mathrm{Ce}$ ment and Concrete Research, Vol. 34, No. 9, 2004, pp. 1683-1696. http://dx.doi.org/10.1016/j.cemconres.2004.03.026

[8] J. Lindgard, “Alkali-Silica Reactions: Literature Review on Parameters Influencing Laboratory Performance Testing," Cement and Concrete Research, Vol. 42, No. 2, 2012, pp. 223-243. http://dx.doi.org/10.1016/j.cemconres.2011.10.004

[9] M.-A. Berube and J. Duchesne, "Does Silica Fume Merely
Postpone Expansion Due to Alkali-Aggregate Reactivity?” Construction and .Building Materials, Vol. 7, No. 3, 1993, pp. 137-143. http://dx.doi.org/10.1016/0950-0618(93)90050-M

[10] M. Thomas, B. Fournier, K. Folliard, J. Ideker and M. Shehata, "Test Methods for Evaluating Preventive Measures for Controlling Expansion Due to Alkali-Silica Reaction in Concrete," Cement and Concrete Research, Vol. 36, No. 10, 2006, pp. 1842-1856.

http://dx.doi.org/10.1016/j.cemconres.2006.01.014

[11] A. S. Brykov, M. E Voronkov and M. V. Mokeev, “Conversion of Silica-Containing Additives upon Testing of Cement Compositions for Alkali Expansion," Russian Journal of Applied Chemistry, Vol. 85, No. 9, 2012, pp. 1311-1318. http://dx.doi.org/10.1134/S1070427212090030

[12] M. D. Andersen, H. J. Jakobsen and J. Skibsted, "Characterization of White Portland Cement Hydration and the C-S-H Structure in the Presence of Sodium Aluminate by 27Al and 29Si MAS NMR Spectroscopy," Cement and Concrete Research, Vol. 34, No. 5, 2004, pp. 857-868. http://dx.doi.org/10.1016/j.cemconres.2003.10.009

[13] C. A. Love, I. G. Richardson and A. R. Brough, "Composition and Structure of C-S-H in white Portland Cement $-20 \%$ Metakaolin Pastes Hydrated at $25^{\circ} \mathrm{C}$," Cement and Concrete Research, Vol. 37, No. 2, 2007, pp. 109-117. http://dx.doi.org/10.1016/j.cemconres.2006.11.012

[14] I. G. Richardson, "The Nature of C-S-H in Hardened Cements," Cement and Concrete Research, Vol. 29, No. 8, 1999, pp. 1131-1147. http://dx.doi.org/10.1016/S0008-8846(99)00168-4

[15] G. K. Sun, J. F. Young and R. J. Kirkpatrick, “The Role of Al in C-S-H: NMR, XRD, and Compositional Results for Precipitated Samples," Cement and Concrete Research, Vol. 36, No. 1, 2006, pp. 18-29. http://dx.doi.org/10.1016/j.cemconres.2005.03.002

[16] A. S. Brykov, R. T. Kamaliev and M. V. Mokeev, "Influence of Ultra-Dispersed Silicas on Portland Cement Hydration," Russian Journal of Applied Chemistry, Vol. 83, No. 2, 2010, pp. 208-213. http://dx.doi.org/10.1134/S1070427210020059

[17] T. Chappex and K. Scrivener, "The Influence of Aluminium on the Dissolution of Amorphous Silica and Its Relation to Alkali Silica Reaction," Cement and Concrete Research, Vol. 42, No. 12, 2012, pp. 1645-1649. http://dx.doi.org/10.1016/j.cemconres.2012.09.009 